\title{
Progress Toward Measles Elimination — African Region, 2013-2016
}

\author{
Balcha G. Masresha, $\mathrm{MD}^{1}$; Meredith G. Dixon, $\mathrm{MD}^{2}$; Jennifer L. Kriss, $\mathrm{PhD}^{2}$; Reggis Katsande, $\mathrm{MBA}^{3}$; Messeret E. Shibeshi, MD 3 ; \\ Richard Luce, $\mathrm{MD}^{4}$; Amadou Fall, MD ; Annick R.G.A. Dosseh, PhD ${ }^{5}$; Charles R. Byabamazima, $\mathrm{MD}^{3}$; Alya J. Dabbagh, PhD ${ }^{6}$; \\ James L. Goodson, $\mathrm{MPH}^{2}$; Richard Mihigo, $\mathrm{MD}^{1}$
}

In 2011, the 46 World Health Organization (WHO) African Region (AFR) member states established a goal of measles elimination* by 2020 , by achieving 1$) \geq 95 \%$ coverage of their target populations with the first dose of measlescontaining vaccine (MCV1) at national and district levels; 2) $\geq 95 \%$ coverage with measles-containing vaccine (MCV) per district during supplemental immunization activities (SIAs); and 3) confirmed measles incidence of $<1$ case per 1 million population in all countries (1). Two key surveillance performance indicator targets include 1) investigating $\geq 2$ cases of nonmeasles febrile rash illness per 100,000 population annually, and 2) obtaining a blood specimen from $\geq 1$ suspected measles case in $\geq 80 \%$ of districts annually (2). This report updates the previous report (3) and describes progress toward measles elimination in AFR during 2013-2016. Estimated regional MCV1 coverage ${ }^{\dagger}$ increased from $71 \%$ in 2013 to $74 \%$ in $2015 . \$$ Seven $(15 \%)$ countries achieved $\geq 95 \%$ MCV1 coverage in 2015.9 The number of countries providing a routine second $\mathrm{MCV}$ dose (MCV2) increased from $11(24 \%)$ in 2013 to $23(49 \%)$ in 2015 . Forty-one (79\%) of 52 SIAs** during 2013-2016 reported $\geq 95 \%$ coverage. Both surveillance targets were met in 19 (40\%)

\footnotetext{
* Measles elimination is defined as the absence of endemic measles virus transmission in a defined geographic area (e.g., region or country) for $\geq 12$ months in the presence of a well performing surveillance system. Regional verification of measles elimination takes place after 36 months of interrupted endemic measles virus transmission. More information is available in the WHO Framework for Elimination of Measles and Rubella published in 2013 (http://www.who.int/wer/2013/wer8809.pdf?ua=1).

$\dagger$ http://www.who.int/immunization_monitoring/routine/immunization_ coverage/en/index $4 . h$ tm.

$\$$ As of March 31, 2017, coverage estimates were not yet available for 2016; thus, the coverage estimates for 2015 were used in this analysis.

9 The number of countries used in the denominator is 46 for 2013 and 47 for 2014-2016. South Sudan did not join the World Health Organization (WHO) African Region (AFR) until late 2013 and was not included in the count for 2013.

** Supplemental immunization activities (SIAs) are carried out using two target age ranges. An initial, nationwide catch-up SIA focuses on all children aged 9 months-14 years, with the goal of eliminating susceptibility to measles in the general population. Periodic follow-up SIAs then focus on all children born since the last SIA. Follow-up SIAs generally are conducted nationwide every 2-4 years, depending on routine immunization coverage, and focus on children aged 9-59 months; their goal is to eliminate any measles susceptibility that has developed in recent birth cohorts and to protect children who did not respond to MCV1. The target age range for follow-up SIAs might be widened to include older children based on the measles susceptibility pattern in countries. Administrative coverage is calculated as the number of vaccine doses provided divided by the total number of children in the age group targeted, multiplied by 100 .
}

countries in 2016. Confirmed measles incidence in AFR decreased from 76.3 per 1 million population to 27.9 during 2013-2016. To eliminate measles by 2020, AFR countries and partners need to 1 ) achieve $\geq 95 \%$ 2-dose MCV coverage through improved immunization services, including second dose (MCV2) introduction; 2) improve SIA quality by preparing $12-15$ months in advance, and using readiness, intra-SIA, and post-SIA assessment tools; 3) fully implement elimination-standard surveillance $\left.{ }^{\dagger \dagger} ; 4\right)$ conduct annual district-level risk assessments; and 5) establish national committees and a regional commission for the verification of measles elimination.

\section{Immunization Activities}

WHO and the United Nations Children's Fund (UNICEF) estimate vaccination coverage using annual governmentreported administrative data and data from independent surveys. During 2013-2015, the estimated MCV1 coverage in AFR increased from $71 \%$ to $74 \%$, while the number of AFR countries with $\geq 95 \%$ MCV1 coverage decreased from eight (17\%) to seven (15\%) (Table 1). In 2015, national MCV1 coverage was highest in Mauritius (99\%), Tanzania (99\%), and Seychelles (98\%), and lowest in South Sudan (20\%), Equatorial Guinea (27\%), and the Central African Republic (49\%). The number of countries providing a routine MCV2 dose increased from 11 (24\%) in 2013 to 23 (49\%) in 2015. Estimated regional MCV2 coverage increased from $7 \%$ in 2013 to $18 \%$ in 2015. During 2013-2016, approximately 300 million children received MCV during 52 SIAs conducted in $42(89 \%)$ countries (Table 2). In 41 (79\%) SIAs, reported administrative coverage was $\geq 95 \%$. Among 25 (48\%) SIAs for which a post-SIA coverage survey was conducted, estimated coverage of $\geq 95 \%$ was achieved in eight $(32 \%)$.

\footnotetext{
†† The 2015 WHO African Regional Guidelines for Measles and Rubella Surveillance recommend that all Member States implement case-based measles surveillance with lab confirmation, and that countries with sustained low incidence of measles implement elimination-standard surveillance. The surveillance system currently used and the indicators utilized to measure performance by 44 of 47 countries in the Africa Region, have been in place since 2002, and are not considered sensitive enough in countries with very low measles incidence nearing measles elimination. However, to move to a more sensitive system of elimination-standard surveillance, the financial and human resources required to investigate and obtain a blood specimen for every suspected case do not currently exist. The indicators used in this analysis are the main measles surveillance indicators.
} 
TABLE 1. Estimated coverage with the first dose (MCV1)* and second dose (MCV2)*, + of measles-containing vaccine, number of confirmed measles cases, ${ }^{\S}$ and confirmed measles incidence per 1 million population," by country - World Health Organization (WHO) African Region, 2013-2016

\begin{tabular}{|c|c|c|c|c|c|c|c|c|c|c|}
\hline \multirow[b]{3}{*}{ Country } & \multicolumn{3}{|c|}{2013} & \multicolumn{3}{|c|}{2014} & \multicolumn{3}{|c|}{2015} & \multirow{3}{*}{$\frac{2016}{\begin{array}{c}\text { No. of } \\
\text { confirmed cases } \\
\text { (incidence }\end{array} \text { ) }}$} \\
\hline & \multicolumn{2}{|c|}{ Coverage (\%) } & \multirow{2}{*}{$\begin{array}{c}\text { No. of } \\
\text { confirmed cases } \\
\text { (incidence") }\end{array}$} & \multicolumn{2}{|c|}{ Coverage $(\%)$} & \multirow{2}{*}{$\begin{array}{c}\text { No. of } \\
\text { confirmed cases } \\
\text { (incidence") }\end{array}$} & \multicolumn{2}{|c|}{ Coverage $(\%)$} & \multirow{2}{*}{$\begin{array}{l}\text { No. of } \\
\text { confirmed cases } \\
\text { (incidence }{ }^{\S} \text { ) }\end{array}$} & \\
\hline & MCV1 & $\mathrm{MCV}^{\dagger}$ & & MCV1 & $\mathrm{MCV}^{+}$ & & MCV1 & $\mathrm{MCV}^{\dagger}$ & & \\
\hline Algeria & 95 & 93 & $0(0.0)$ & 95 & 99 & $0(0.0)$ & 95 & 99 & $62(1.6)$ & $27(0.7)$ \\
\hline Angola & 66 & - & $6,297(268.5)$ & 60 & - & $11,648(480.8)$ & 55 & 26 & $67(2.7)$ & $33(1.3)$ \\
\hline Benin & 68 & - & 735 (71.2) & 68 & - & $768(72.5)$ & 75 & - & $53(4.9)$ & $90(8.1)$ \\
\hline Botswana & 97 & 83 & $1(0.5)$ & 97 & 85 & 88 (39.6) & 97 & 85 & $20.9)$ & $1(0.4)$ \\
\hline Burkina Faso & 82 & - & $431(25.2)$ & 88 & 17 & $433(24.6)$ & 88 & 50 & $99(5.5)$ & $222(11.9)$ \\
\hline Burundi & 98 & 51 & $0(0.0)$ & 94 & 60 & $5(0.5)$ & 93 & 65 & $9(0.8)$ & $17(1.5)$ \\
\hline Cameroon & 83 & - & $766(34.5)$ & 80 & - & $720(31.6)$ & 79 & - & $1,785(76.5)$ & $324(13.5)$ \\
\hline Cape Verde & 91 & 89 & $0(0.0)$ & 93 & 79 & $0(0.0)$ & 92 & 95 & $0(0.0)$ & $0(0.0)$ \\
\hline Central African Republic & 25 & - & $370(78.5)$ & 49 & - & $212(44.1)$ & 49 & - & $147(30.0)$ & $156(31.2)$ \\
\hline Chad & 59 & - & $185(14.1)$ & 54 & - & $1,237(91.0)$ & 62 & - & $435(31.0)$ & $147(10.1)$ \\
\hline Comoros & 82 & - & $0(0.0)$ & 80 & - & $0(0.0)$ & 81 & - & $0(0.0)$ & $0(0.0)$ \\
\hline Congo & 80 & - & $123(28.0)$ & 80 & - & $70(15.5)$ & 80 & - & 1,358 (293.9) & $292(61.6)$ \\
\hline Cote d'Ivoire & 76 & - & $48(2.2)$ & 62 & - & $50(2.3)$ & 72 & - & $40(1.8)$ & $52(2.2)$ \\
\hline Democratic Republic of Congo & 76 & - & $2,470(34.0)$ & 77 & - & $1,595(21.3)$ & 79 & - & 4,471 (57.9) & $4,790(60.1)$ \\
\hline Equatorial Guinea & 42 & - & $6(7.5)$ & 44 & - & $9(11.0)$ & 27 & - & $1,232(1,457.9)$ & $1,685(1,937.7)$ \\
\hline Eritrea & 94 & - & $47(9.4)$ & 90 & - & $1(0.2)$ & 85 & 75 & $91(17.4)$ & $59(11.0)$ \\
\hline Ethiopia & 62 & - & $6,029(63.8)$ & 70 & - & $12,485(128.8)$ & 78 & - & $16,123(162.2)$ & $4,484(44.0)$ \\
\hline Gabon & 70 & - & $127(77.0)$ & 61 & - & $42(24.9)$ & 68 & - & $37(21.4)$ & $1,274(722.6)$ \\
\hline Gambia & 96 & 53 & $1(0.5)$ & 96 & 73 & $2(1.0)$ & 97 & 77 & $21(10.5)$ & $40(19.5)$ \\
\hline Ghana & 89 & 54 & $318(12.2)$ & 92 & 67 & $143(5.3)$ & 89 & 63 & $51(1.9)$ & $53(1.9)$ \\
\hline Guinea & 62 & - & $39(3.3)$ & 52 & - & $35(2.9)$ & 52 & - & $29(2.3)$ & $130(10.0)$ \\
\hline Guinea-Bissau & 69 & - & $0(0.0)$ & 69 & - & $0(0.0)$ & 69 & - & $0(0.0)$ & $0(0.0)$ \\
\hline Kenya & 73 & - & 215 (4.9) & 79 & - & $356(7.9)$ & 75 & 28 & $110(2.4)$ & $61(1.3)$ \\
\hline Lesotho & 90 & 82 & $2(1.0)$ & 90 & 82 & 4 (1.9) & 90 & 82 & $2(0.9)$ & $13(6.0)$ \\
\hline Liberia & 74 & - & $0(0.0)$ & 58 & - & $0(0.0)$ & 64 & - & $433(96.1)$ & $391(84.7)$ \\
\hline Madagascar & 63 & - & $8(0.3)$ & 64 & - & $3(0.1)$ & 58 & - & $7(0.3)$ & $22(0.9)$ \\
\hline Malawi & 88 & - & $1(0.1)$ & 85 & - & $2(0.1)$ & 87 & 8 & $19(1.1)$ & $4(0.2)$ \\
\hline Mali & 80 & - & $308(18.6)$ & 80 & - & $274(16.0)$ & 76 & - & $240(13.6)$ & 107 (5.9) \\
\hline Mauritania & 80 & - & $3(0.8)$ & 84 & - & $14(3.5)$ & 70 & - & $1(0.2)$ & $13(3.1)$ \\
\hline Mauritius & 99 & 85 & $0(0.0)$ & 98 & 85 & $0(0.0)$ & 99 & 85 & $0(0.0)$ & $0(0.0)$ \\
\hline Mozambique & 85 & - & $57(2.2)$ & 85 & - & $80(2.9)$ & 85 & - & $78(2.8)$ & $84(2.9)$ \\
\hline Namibia & 82 & - & 495 (210.9) & 83 & - & 718 (298.8) & 85 & - & $216(87.8)$ & $13(5.2)$ \\
\hline Niger & 76 & - & $790(43.0)$ & 72 & 3 & $294(15.4)$ & 73 & 16 & $603(30.3)$ & $591(28.5)$ \\
\hline Nigeria & 47 & - & $50,585(292.7)$ & 51 & - & $4,470(25.2)$ & 54 & - & $11,494(63.1)$ & $11,499(61.5)$ \\
\hline Rwanda & 95 & - & $17(1.5)$ & 97 & - & $5(0.4)$ & 97 & 87 & $1(0.1)$ & $57(4.8)$ \\
\hline Sao Tome and Principe & 91 & - & $0(0.0)$ & 92 & 71 & $0(0.0)$ & 93 & 76 & $0(0.0)$ & $0(0.0)$ \\
\hline Senegal & 84 & - & $13(0.9)$ & 80 & 13 & $38(2.6)$ & 80 & 54 & $58(3.8)$ & $159(10.2)$ \\
\hline Seychelles & 97 & 97 & $0(0.0)$ & 99 & 98 & $0(0.0)$ & 98 & 98 & $0(0.0)$ & $0(0.0)$ \\
\hline Sierra Leone & 83 & - & $13(2.1)$ & 78 & - & $44(7.0)$ & 76 & 60 & $139(21.5)$ & 195 (29.6) \\
\hline South Africa & 66 & 53 & $61(1.1)$ & 70 & 60 & $98(1.8)$ & 76 & 63 & $18(0.3)$ & $24(0.4)$ \\
\hline South Sudan & 30 & - & $0(0.0)$ & 22 & - & $0(0.0)$ & 20 & - & 341 (27.6) & 845 (66.4) \\
\hline Swaziland & 85 & 89 & $0(0.0)$ & 86 & 89 & $0(0.0)$ & 78 & 89 & $0(0.0)$ & $1(0.8)$ \\
\hline Tanzania & 99 & - & 191 (3.8) & 99 & 29 & $61(1.2)$ & 99 & 57 & $19(0.4)$ & $36(0.7)$ \\
\hline Togo & 72 & - & $321(46.3)$ & 82 & - & 168 (23.6) & 85 & - & $21(2.9)$ & 29 (3.9) \\
\hline Uganda & 82 & - & 452 (12.4) & 82 & - & $313(8.3)$ & 82 & - & $478(12.2)$ & $250(6.2)$ \\
\hline Zambia & 80 & - & $1(0.1)$ & 85 & 33 & $16(1.0)$ & 90 & 47 & $20(1.2)$ & $7(0.4)$ \\
\hline Zimbabwe & 93 & - & $3(0.2)$ & 92 & - & $65(4.3)$ & 86 & - & $1(0.1)$ & $2(0.1)$ \\
\hline African Region & 71 & 7 & $71,529(76.3)$ & 72 & 11 & $36,566(38.0)$ & 74 & 18 & $40,411(40.9)$ & $28,279(27.9)$ \\
\hline
\end{tabular}

* WHO-United Nations Children's Fund (UNICEF) estimate.

† Cells containing"-" indicate that the corresponding country has not yet introduced MCV2.

$\S$ Measles case-based surveillance. Confirmed cases were defined by laboratory criteria, epidemiologic linkage, or clinical criteria. Laboratory-confirmed was defined as having a measles-specific immunoglobulin M-positive test result and not receiving a measles vaccination during the 30 days before rash onset. Epidemiologically linked was defined as meeting the suspected measles case definition and having contact (i.e., lived in the same district or an adjacent district, with plausibility of transmission) with a patient with a laboratory-confirmed measles case with rash onset within the preceding 30 days. Clinically compatible was defined as meeting the case definition for measles, with no specimen available for laboratory testing and no evidence of epidemiologic linkage to a laboratory-confirmed case. A suspected measles case was defined as an illness characterized by rash, fever, and one or more of the following symptoms: conjunctivitis, coryza, or cough, or an illness in any patient in whom the clinician suspected measles.

"Incidence per 1 million population was calculated using the United Nations Population Division World Population Prospects: 2015 revision. 
TABLE 2. Characteristics of national and subnational measles supplementary immunization activities (SIAs), ${ }^{*}, \mathrm{t}, \S$ by year and country — World Health Organization African Region, 2013-2016

\begin{tabular}{|c|c|c|c|c|c|c|c|c|}
\hline \multirow[b]{2}{*}{ Year } & \multirow[b]{2}{*}{ Country } & \multirow[b]{2}{*}{ Type of SIA* } & \multirow[b]{2}{*}{$\begin{array}{l}\text { Age group } \\
\text { targeted }\end{array}$} & \multirow[b]{2}{*}{$\begin{array}{c}\text { Extent } \\
\text { of SIA }\end{array}$} & \multicolumn{2}{|c|}{ Children reached in target age group } & \multirow{2}{*}{$\begin{array}{c}\% \text { of districts } \\
\text { with } \geq 95 \% \\
\text { administrative } \\
\text { coverage }{ }^{\uparrow, * *}\end{array}$} & \multirow{2}{*}{$\begin{array}{l}\text { Estimated } \\
\text { SIA coverage by } \\
\text { survey }(\%)^{* *}\end{array}$} \\
\hline & & & & & No. & $\begin{array}{l}\text { Administrative } \\
\text { coverage }(\%)^{\dagger, \emptyset}\end{array}$ & & \\
\hline 2013 & Botswana & Follow-up M & $9-59 m$ & $\mathrm{~N}$ & 198,341 & 95 & 54 & - \\
\hline 2013 & Cape Verde & Catch-up MR & $9 m-24 y$ & $\mathrm{~N}$ & 240,166 & 95 & 46 & - \\
\hline 2013 & Comoros & Follow-up M & $6-59 \mathrm{~m}$ & $\mathrm{~N}$ & 86,516 & 86 & 59 & 93 \\
\hline 2013 & Congo & Follow-up M & $6-59 m$ & $\mathrm{~N}$ & 726,979 & 92 & 58 & 86 \\
\hline 2013 & Democratic Republic of the Congo & Follow-up M & $6 m-9 y$ & SN & $11,019,958$ & 100 & - & - \\
\hline 2013 & Ethiopia & Follow-up M & $9-59 \mathrm{~m}$ & $\mathrm{~N}$ & $11,608,063$ & 99 & 66 & 91 \\
\hline 2013 & Ghana & Catch-up MR & $9 m-14 y$ & $\mathrm{~N}$ & $11,062,605$ & 99 & 70 & 96 \\
\hline 2013 & Lesotho & Follow-up M & $9-59 \mathrm{~m}$ & $\mathrm{~N}$ & 147,676 & 73 & 90 & 92 \\
\hline 2013 & Madagascar & Follow-up M & $9-59 m$ & $\mathrm{~N}$ & $3,316,542$ & 92 & 56 & 84 \\
\hline 2013 & Malawi & Follow-up M & $9-59 m$ & $\mathrm{~N}$ & $2,405,108$ & 105 & 100 & 96 \\
\hline 2013 & Mozambique & Follow-up M & $9-59 \mathrm{~m}$ & $\mathrm{~N}$ & $4,078,637$ & 102 & 95 & 81 \\
\hline 2013 & Nigeria & Follow-up M & 9-59 m & SN & $30,579,666$ & 103 & - & 75 \\
\hline 2013 & Rwanda & Catch-up MR & $9 m-14 y$ & $\mathrm{~N}$ & $4,391,081$ & 103 & 90 & 98 \\
\hline 2013 & Senegal & Catch-up MR & $9 m-14 y$ & $\mathrm{~N}$ & $6,097,155$ & 101 & 76 & 97 \\
\hline 2013 & South Africa & Follow-up M & 6-59 m & $\mathrm{N}$ & $4,186,191$ & 100 & 60 & - \\
\hline 2013 & Swaziland & Follow-up M & $6-59 m$ & $\mathrm{~N}$ & 119,207 & 97 & - & 91 \\
\hline 2013 & Togo & Follow-up M & $9 m-9 y$ & $\mathrm{~N}$ & $1,641,635$ & 96 & 83 & - \\
\hline 2014 & Angola & Follow-up M & $6 m-9 y$ & $\mathrm{~N}$ & $7,829,940$ & 117 & 84 & 97 \\
\hline 2014 & Benin & Follow-up M & $9 m-9 y$ & $\mathrm{~N}$ & $3,009,405$ & 101 & 82 & 97 \\
\hline 2014 & Burkina Faso & Catch-up MR & $9 m-14 y$ & $\mathrm{~N}$ & $8,517,508$ & 107 & 100 & - \\
\hline 2014 & Chad & Follow-up M & $6 m-9 y$ & SN & $2,549,188$ & 103 & 94 & - \\
\hline 2014 & Côte d'Ivoire & Follow-up M & $6 m-9 y$ & $\mathrm{~N}$ & $9,640,512$ & 92 & 95 & 95 \\
\hline 2014 & Democratic Republic of Congo & Follow-up M & $6 m-9 y$ & SN & $20,699,401$ & 101 & 87 & - \\
\hline 2014 & Mauritania & Follow-up M & $9 m-14 y$ & $\mathrm{~N}$ & $1,489,563$ & 105 & 92 & - \\
\hline 2014 & South Sudan & Follow-up M & 6-59m & $\mathrm{N}$ & $1,715,139$ & 122 & 98 & 77 \\
\hline 2014 & Tanzania & Catch-up MR & $9 m-14 y$ & $\mathrm{~N}$ & $20,529,629$ & 97 & 59 & 89 \\
\hline 2015 & Benin & Follow-up M & $9 m-9 y$ & $\mathrm{~N}$ & 408,511 & 102 & - & - \\
\hline 2015 & Cameroon & Catch-up MR & $9 m-14 y$ & $\mathrm{~N}$ & $9,229,739$ & 98 & 80 & 89 \\
\hline 2015 & Eritrea & Follow-up M & $9-59 \mathrm{~m}$ & $\mathrm{~N}$ & 350,765 & 80 & 36 & - \\
\hline 2015 & Guinea-Bissau & Follow-up M & $9-59 \mathrm{~m}$ & $\mathrm{~N}$ & 223,673 & 86 & 18 & - \\
\hline 2015 & Liberia & Follow-up M & 6-59 m & $\mathrm{N}$ & 596,545 & 99 & 80 & 90 \\
\hline 2015 & Mali & Follow-up M & $9 m-14 y$ & $\mathrm{~N}$ & $9,312,619$ & 112 & 91 & 94 \\
\hline 2015 & Niger & Follow-up M & $9-59 \mathrm{~m}$ & $\mathrm{~N}$ & $3,299,923$ & 96 & 75 & - \\
\hline 2015 & Nigeria & Follow-up M & $9-59 \mathrm{~m}$ & $\mathrm{~N}$ & $43,134,811$ & 110 & 88 & 85 \\
\hline 2015 & Sierra Leone & Follow-up M & $9-59 \mathrm{~m}$ & $\mathrm{~N}$ & $1,205,865$ & 97 & 71 & - \\
\hline 2015 & Togo & Follow-up M & $9 m-9 y$ & SN & 820,335 & 99 & 94 & - \\
\hline 2015 & Uganda & Follow-up M & 6-59 m & $\mathrm{N}$ & $6,349,182$ & 95 & 56 & - \\
\hline 2015 & Zimbabwe & Catch-up MR & $9 m-14 y$ & $\mathrm{~N}$ & $5,337,029$ & 103 & 100 & 94 \\
\hline 2016 & Botswana & Catch-up MR & $9 m-14 y$ & $\mathrm{~N}$ & 674,150 & 95 & 67 & - \\
\hline 2016 & Central African Republic & Follow-up M & 6-59 m & $\mathrm{N}$ & $1,529,441$ & 84 & 20 & - \\
\hline 2016 & Chad & Follow-up M & $6-59 m$ & $\mathrm{~N}$ & $2,342,341$ & 112 & 99 & - \\
\hline 2016 & Comoros & Follow-up M & $6-59 m$ & $\mathrm{~N}$ & 80,614 & 74 & 41 & - \\
\hline 2016 & Democratic Republic of Congo & Follow-up M & $6-59 m$ & $\mathrm{~N}$ & $10,921,820$ & 101 & 93 & - \\
\hline 2016 & Equatorial Guinea & Follow-up M & 6-59m & $\mathrm{N}$ & 127,874 & 85 & 61 & - \\
\hline 2016 & Gambia & Catch-up MR & $9 m-14 y$ & $\mathrm{~N}$ & 779,654 & 97 & 86 & - \\
\hline 2016 & Guinea & Follow-up M & $9-59 \mathrm{~m}$ & $\mathrm{~N}$ & $2,412,923$ & 103 & 94.7 & 92.7 \\
\hline 2016 & Kenya & Catch-up MR & $9 m-14 y$ & $\mathrm{~N}$ & $19,154,577$ & 101 & 77 & 95 \\
\hline 2016 & Madagascar & Follow-up M & $9-59 \mathrm{~m}$ & $\mathrm{~N}$ & $3,547,456$ & 95 & 75 & - \\
\hline 2016 & Namibia & Catch-up MR & $9 m-39 y$ & $\mathrm{~N}$ & $1,908,193$ & 103 & 77 & - \\
\hline 2016 & Sao Tome and Principe & Catch-up MR & $9 m-14 y$ & $\mathrm{~N}$ & 77,285 & 107 & 100 & - \\
\hline 2016 & Swaziland & Catch-up MR & $9 m-14 y$ & $\mathrm{~N}$ & 373,508 & 90 & - & 94 \\
\hline 2016 & Zambia & Catch-up MR & $9 m-14 y$ & $\mathrm{~N}$ & $7,741,505$ & 108 & 97 & - \\
\hline TOTAL & - & - & - & - & $299,826,149$ & 102 & - & - \\
\hline
\end{tabular}

Abbreviations: $M=$ measles vaccination; $M R=$ measles-rubella vaccination; $m=$ months; $N=$ national; $S N=$ subnational; $y=$ years.

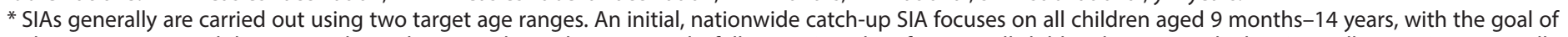

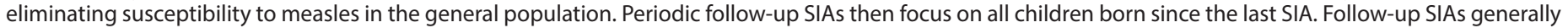

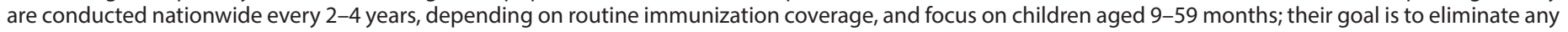

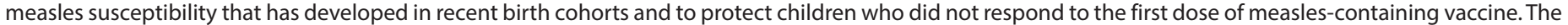

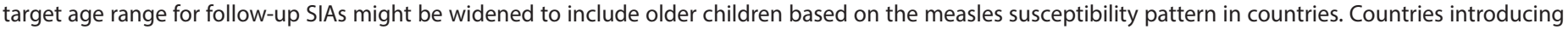
rubella vaccine do so via wide age-range combined measles-rubella vaccine campaigns.

† Data source is the World Health Organization, African Region. Data were last updated March 10, 2017.

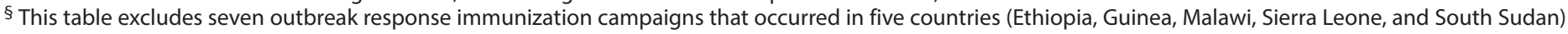
and which vaccinated approximately 40.4 million children.

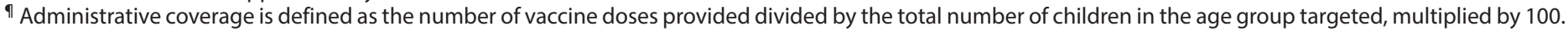
** Cells containing " - " indicate that data was not available at time of publication or that no coverage survey was performed. 


\section{Surveillance Activities}

Countries performing measles case-based surveillance electronically report surveillance data ${ }^{\$ \$}$ weekly to the WHO AFR office. Measles case-based surveillance involves completing a case investigation form 99 and collecting a blood specimen for laboratory testing (2). Suspected measles cases are confirmed by laboratory testing, epidemiologic linkage to a confirmed case, or by clinical criteria.*** During 2013-2016, all but three AFR countries ${ }^{\dagger \dagger \dagger}$ conducted case-based surveillance with access to standardized quality-controlled testing at 47 laboratories within the WHO Global Measles and Rubella Laboratory Network ${ }^{\$ \$}$ (4). During 2013-2016, the number of countries that met both surveillance targets (i.e., investigated two or more cases of nonmeasles febrile rash illness per 100,000 population annually and obtained a blood specimen from at least one suspected measles case in $\geq 80 \%$ of districts) (19 countries), one of the surveillance targets (12), and neither surveillance target (16) remained stable (Figure). Although the total number

$\$ \$$ Case-based surveillance is the collection of epidemiologic information about each individual case; effective case-based measles surveillance includes confirmatory laboratory testing or epidemiologic linkage to a previous, laboratory-confirmed case.

IS For countries implementing elimination-standard case-based surveillance, WHO recommends that information be collected on 12 core variables: name, sex, age/date of birth, date of rash onset, date of notification, date of investigation, date of specimen collection, vaccination status, date of last measles vaccination, district of residence, reporting district, and travel history 7-21 days before date of rash onset.

*** Measles cases are defined as laboratory confirmed, epidemiologically confirmed, or clinically compatible. Laboratory confirmed cases are suspected measles cases with detectable measles virus-specific immunoglobulin class $M$ antibodies, or from whom measles virus can be isolated or measles virus RNA can be detected in appropriate clinical specimens by a proficient laboratory. Epidemiologically linked confirmed measles cases are those suspected measles cases that have not been confirmed by a laboratory but are geographically and temporally related to a laboratory-confirmed case or, in the event of a chain of transmission, to another epidemiologically confirmed measles case, with dates of rash onset occurring 7-21 days apart. Clinically compatible measles cases are a suspected measles cases with fever and maculopapular rash and at least one of the following: cough, coryza, or conjunctivitis, for which no adequate clinical specimen was collected and which have not been linked epidemiologically to a laboratory-confirmed case of measles or to laboratoryconfirmed case of another communicable disease.

$\dagger \dagger \dagger$ Mauritius, Sao Tome and Principe, and Seychelles performed clinical surveillance, which entails notifying and reporting suspected cases using symptom-based case definitions, without any laboratory testing, to the national level in a timely manner. Clinical surveillance is performed because these three countries did not have national laboratories for measles testing. These countries did not report through the AFR case-based surveillance system for 2013-2106. WHO is supporting these countries to establish national serologic laboratories.

$\$ \$ \$$ The WHO Global Measles and Rubella Laboratory Network supports standardized methods and quality assurance measures in national laboratories across countries, as well as in three regional reference laboratories (Abidjan, Cote d'Ivoire; Entebbe, Uganda; and Johannesburg, South Africa). The lab network sequences the 450 nucleotides coding for the carboxy-terminal 150 amino acids of the nucleoprotein. Data (as of March 29, 2017) are available from the Measles Nucleotide Surveillance database. http://www.who-measles. org/Public/Web_Front/main.php. of countries per category remained constant, performance declined in seven (15\%) countries, improved in nine (19\%), and was unchanged in $31(66 \%)$.

\section{Disease Incidence}

Overall, 176,785 confirmed measles cases were reported in AFR through case-based surveillance during 2013-2016 (Table 1). The number of confirmed measles cases declined $60 \%$, from 71,529 in 2013 to 28,279 in 2016 . During 2013-2016, a total of 103,161 (60\%) reported measles cases occurred among children aged 9-59 months, 79\% of whom were either unvaccinated or had unknown vaccination status. Confirmed measles incidence decreased 63\% from 76.3 per 1 million population in 2013 to 27.9 in 2016 (Table 1). The largest percentage decreases in incidence occurred in Angola (99\%), Namibia (97\%), and Togo (92\%). The highest confirmed measles incidences in 2016 were reported in Equatorial Guinea (1,938 per 1 million), Gabon (723), and Liberia (85). The number of countries that reported less than one case per 1 million population decreased from 19 (41\%) to 15 (32\%). During 2013-2016, 249 measles virus genotype results were reported from 14 (30\%) countries; all were genotype B3.

\section{Discussion}

Although measles incidence decreased 63\% in AFR during 2013-2016, the region did not meet vaccination coverage, surveillance, and disease incidence targets needed to achieve measles elimination by 2020. During 2013-2015, estimated MCV1 coverage increased only 3\%, and in 2015 was $<95 \%$ in $87 \%$ of AFR countries. Among the estimated 8.9 million infants in AFR who did not receive MCV1 in 2015, approximately 4.8 million (54\%) resided in Nigeria (3 million), Ethiopia (0.7 million), the Democratic Republic of the Congo (DRC) (0.6 million), and Angola (0.5 million) (4). WHO recommends that all countries include a second routine dose of MCV in their national vaccination schedules, irrespective of the level of MCV1 coverage (5); only half of all AFR countries have done so. Eliminating the previous stringent MCV1 coverage requirement $\mathbf{9 9}$ allows all countries to introduce MCV2 and establish a well-child visit during the second year of life, providing a timely catch-up opportunity for children missing MCV1 or other vaccines (6). WHO advises continuation of national follow-up SIAs until high population immunity $(\geq 93 \%-95 \%$ coverage) is achieved and sustained in all districts with a routine 2-dose MCV schedule (5).

\footnotetext{
999 Previous WHO recommendations from 2009 regarding the introduction of MCV2 required that national coverage of MCV1 be $\geq 80 \%$ for 3 consecutive years and that in the African region, at least one of the two main surveillance indicators be met for $\geq 2$ years before introducing a second dose of measles vaccine into routine immunization.
} 


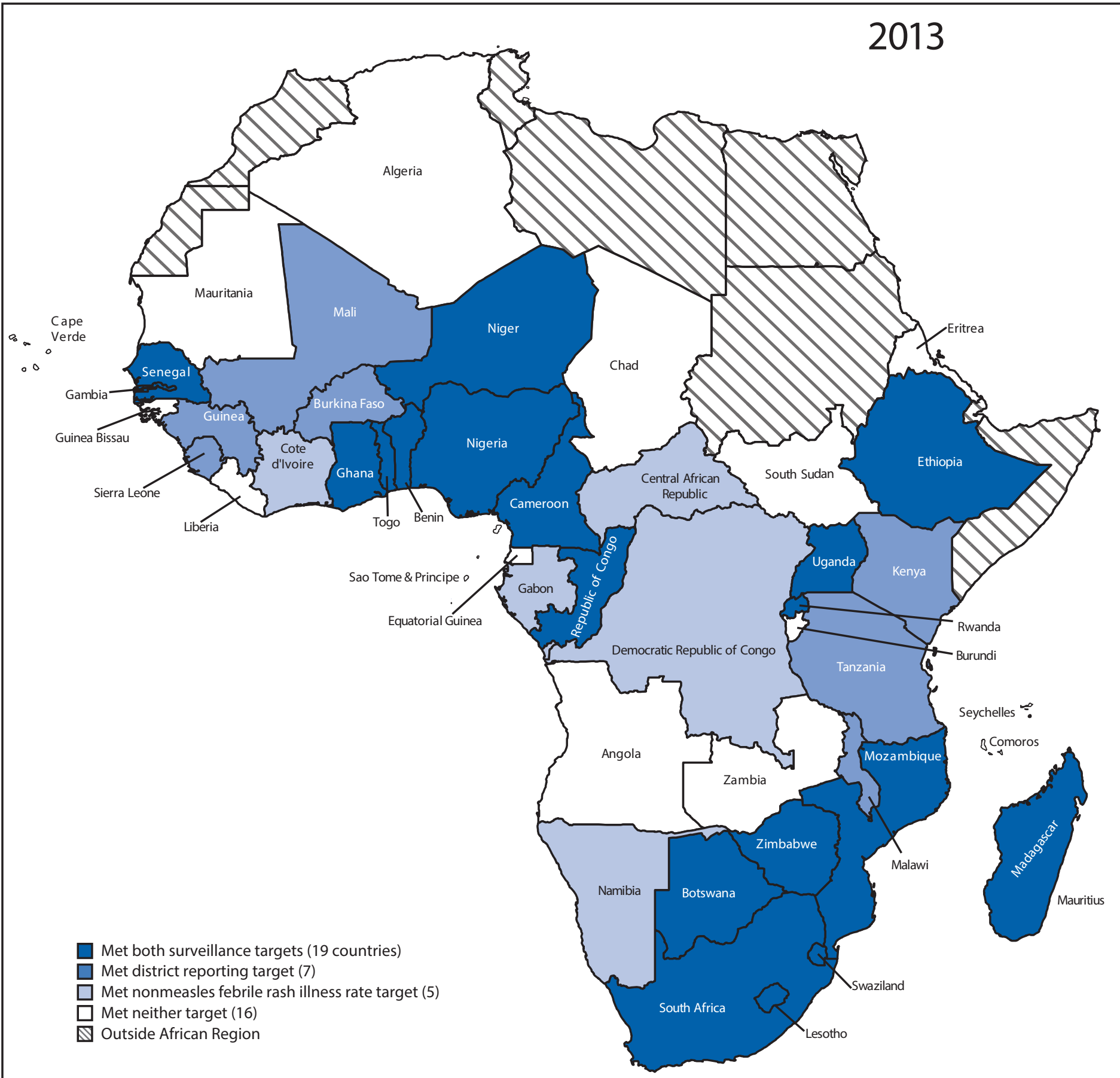

See figure footnote on next page. 


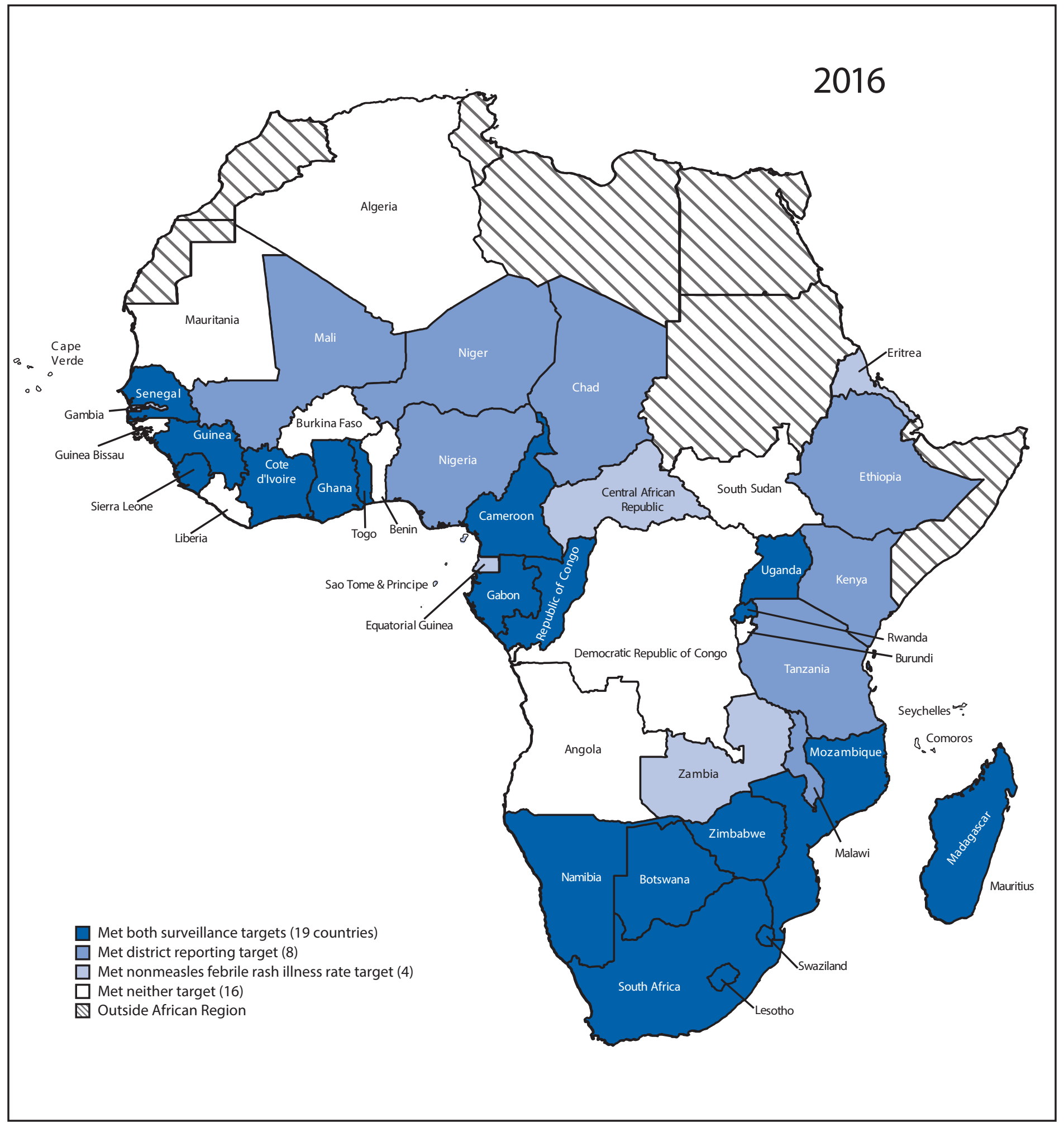

* Two key surveillance performance indicator targets were 1) investigate $\geq 2$ cases of nonmeasles febrile rash illness per 100,000 population annually (nonmeasles febrile rash illness rate target), and 2 ) obtain a blood specimen from $\geq 1$ suspected measles case in $\geq 80 \%$ of districts annually (district reporting target). 


\section{Summary}

What is already known about this topic?

In 2012, the World Health Organization (WHO) and United Nations Children's Fund (UNICEF) estimated first dose of measles-containing vaccine (MCV1) coverage in countries of the WHO African Region (AFR) to be $73 \%$ and $>90 \%$ in 13 (28\%) of 46 AFR countries. Among 35 measles supplementary immunization activities (SIAs) conducted during 2011-2012, 23 (66\%) had $>95 \%$ administrative coverage. Nineteen (44\%) countries met the two key surveillance performance indicator targets. In 2012, only 16 (37\%) countries met the incidence target of $<5$ cases per 1 million population.

What is added by this report?

In 2015, WHO-UNICEF estimated MCV1 coverage in AFR to be $74 \%$; seven (15\%) countries reported $\geq 95 \%$ MCV1 coverage. Among 52 measles SIAs conducted during 2013-2016, 41 (79\%) reported $\geq 95 \%$ administrative coverage. In 2016, 19 (40\%) countries met both surveillance performance indicator targets. In 2016 , only 15 (32\%) countries met the target of $<1$ case per 1 million population.

What are the implications for public health practice?

To eliminate measles by 2020 , AFR countries need to achieve high (95\%) 2-dose measles vaccination coverage, through introduction of a second MCV dose into routine immunization programs, increasing routine immunization coverage, improving SIA quality, fully implementing elimination-standard surveillance, conducting annual district-level risk assessments, and establishing national verification committees and a regional commission for the verification of measles elimination.

During 2013-2016, only 32\% of 25 SIAs where a postcampaign survey was conducted had estimated coverage $\geq 95 \%$, although $>100 \%$ administrative coverage was reported by nearly half of all 52 SIAs. To achieve SIA coverage targets, WHO SIA guidelines and tools ${ }^{* * * *}$ should be used to prepare and implement high-quality campaigns, which are subsequently evaluated by coverage surveys. SIA planning should begin 12-15 months before the SIA, and intra-SIA and postSIA monitoring should be performed to identify low MCV coverage areas so that vaccination of children missed during the SIA can be arranged.

Nearly two-thirds of countries did not attain surveillance indicator targets in 2016, and $15 \%$ of countries had poorer surveillance performance in 2016 than in 2013. Fifteen (32\%) countries achieved the target of $<1$ case per 1 million population in 2016 . However, most confirmed cases detected during 2013-2016 were among children aged 9-59 months who were unvaccinated or had unknown vaccination status. In addition, $84 \%$ of cases were reported from the same four countries that accounted for half of

\footnotetext{
**** Information on planning and implementing high-quality SIAs can be found
} at http://www.who.int/immunization/diseases/measles/en/. children who missed MCV1: Nigeria (44\%), Ethiopia (22\%), Angola (10\%), and DRC (8\%). The recent WHO Measles and Rubella Global Strategic Plan Midterm Review emphasized the limits of MCV coverage data as an indicator and recommended, with SAGE endorsement, using measles disease incidence as another indicator to guide elimination efforts ( 7 ). To measure measles incidence accurately, however, high-quality, case-based surveillance is crucial; this requires increasing resources for full implementation, particularly as countries transition polio eradication resources to other public health priorities.

The findings in this report are subject to at least two limitations. First, vaccination coverage data can be either incorrectly high or low because of inaccurate target population size estimates, erroneous reporting of doses delivered, and inclusion of SIA doses administered to children outside the target age group. Second, surveillance data underestimate the actual number of cases because not all patients with measles seek care, and not all of those seeking care are reported. In 2016, large discrepancies in the number of case-based and aggregate reported measles cases existed, particularly in DRC. ${ }^{\dagger+\dagger}$ Integrated Disease Surveillance and Response system reports of aggregate measles cases in AFR have historically included more measles cases than those reported through casebased surveillance (3). In addition, reported suspected measles cases without confirmatory laboratory testing might actually be rubella cases. Underreporting of measles through case-based surveillance markedly limits case characteristic analysis to guide programs. Strengthening of reporting through case-based surveillance systems is needed to provide more robust data.

To eliminate measles by 2020, AFR countries need to introduce MCV2 and increase coverage through immunization services by better managing human and financial resources, enhancing capacity of health staff for improved access, and increasing demand with community-linked immunization services. SIA quality can be improved through country ownership and SIA preparation starting 12-15 months in advance. Fully implementing laboratory-supported case-based surveillance that meets standards for elimination will require human and financial resources. Annual risk assessments using the WHO programmatic measles risk assessment tool ${ }^{\$ \mathbb{S} \$}$ are necessary

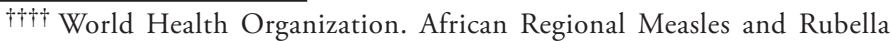
Surveillance feedback summary for 2016. Data as of January 21, 2017.

$\$ \$ S \$$ The WHO measles programmatic risk assessment tool (http://www.who. int/immunization/monitoring_surveillance/routine/measles_assessment/ en) was developed to help national programs identify areas not meeting measles programmatic targets, and based on the findings, guide and strengthen measles elimination program activities and reduce the risk for outbreaks. This Excel-based tool assesses subnational programmatic risk as the sum of indicator scores in four categories: population immunity, surveillance quality, program performance, and threat assessment. Each subnational area is assigned to a programmatic risk category of low, medium, high, or very high risk based on the overall risk score. Scoring for each indicator was developed based on expert consensus.
} 
to identify districts needing surveillance and programmatic strengthening (8). As 2020 approaches, a next step will be to establish national verification committees and a regional commission for the verification of measles elimination (9) that can review and document progress toward measles elimination and provide supportive oversight and advocacy for elimination efforts in AFR.

\section{Acknowledgment}

John Yembu, Global Immunization Division, Center for Global Health, CDC.

\footnotetext{
${ }^{1}$ Immunization and Vaccines Development Program, World Health Organization (WHO), Regional Office for Africa, Brazzaville, Congo; ${ }^{2} \mathrm{Global}$ Immunization Division, Center for Global Health, CDC; ${ }^{3}$ Expanded Program on Immunization, WHO Regional Office for Africa, Inter-Country Support Team, Harare, Zimbabwe; ${ }^{4}$ Expanded Program on Immunization, WHO Regional Office for Africa, Inter-Country Support Team, Libreville, Gabon; 5 Expanded Program on Immunization, WHO Regional Office for Africa, Inter-Country Support Team, Ouagadougou, Burkina Faso; ${ }^{6}$ Department of Immunization, Vaccines, and Biologicals, WHO, Geneva, Switzerland.
}

Corresponding author: Meredith G. Dixon, mgdixon@cdc.gov, 404-279-0493.

\section{References}

1. World Health Organization Regional Committee for Africa. Measles elimination by 2020: a strategy for the African Region. Yamoussoukro, Côte d'Ivoire: World Health Organization Regional Committee for Africa; 2011. http://www.afro.who.int/en/sixty-first-session.html

2. World Health Organization Regional Office for Africa. African regional guidelines for measles and rubella surveillance. Brazzaville, Congo: World Health Organization Regional Office for Africa; 2015. http:// www.afro.who.int/index.php?option $=$ com_docman \&task=doc_ download\&gid $=10814 \&$ Itemid $=2593$

3. Masresha BG, Kaiser R, Eshetu M, et al. Progress toward measles preelimination-African Region, 2011-2012. MMWR Morb Mortal Wkly Rep 2014;63:285-91.

4. World Health Organization. Immunization, vaccines, and biologicals: data, statistics, and graphics. Geneva, Switzerland: World Health Organization; 2014. http://www.who.int/immunization/monitoring_surveillance/data/en/

5. World Health Organization. Measles vaccines: WHO position paperApril 2017. Wkly Epidemiol Rec 2017;92:205-27.

6. World Health Organization. A guide to introducing a second dose of measles vaccine into routine immunization schedules. Geneva, Switzerland: World Health Organization; 2013. http://apps.who.int/iris/ bitstream/10665/85900/1/WHO_IVB_13.03_eng.pdf

7. World Health Organization Strategic Advisory Group of Experts. Midterm review of the Global Measles and Rubella Strategic Plan 2012-2020. Geneva, Switzerland: World Health Organization; 2016. http://apps.who. int/iris/bitstream/10665/251810/1/WER9148.pdf?ua=1

8. Lam E, Schluter WW, Masresha BG, et al. Development of a district-level programmatic assessment tool for risk of measles virus transmission. Risk Anal 2015. Epub May 15, 2015. https://doi.org/10.1111/risa.12409

9. World Health Organization African Region. Report of the Regional Immunization Technical Advisory Group Meeting. Dakar, Senegal: December 12-13, 2016. http://www.who.int/immunization/sage/ meetings/2017/april/4_AFRO_RITAG_Meeting_Report_Final.pdf 